\title{
Making the Connection: Generalized Knowledge Structures in Story Understanding
}

\author{
GaIl McKoon and Roger RatclifF \\ Northwestern University
}

AND

Colleen Seifert

University of Michigan

\begin{abstract}
Six experiments examined the connections in memory between two stories describing the same action sequence. The action sequences represented script-like MOP structures such as eating at a restaurant, like those proposed by Schank (1982. Dynamic memory: A theory of reminding and learning in computers and people. New York: Cambridge University Press). In the experimental procedure, subjects read a long list of stories, and then, after reading all the stories, they were presented with a list of phrases for which they were required to make old/new recognition judgments. Connections among the stories in memory were examined with pairs of phrases placed in the test list such that a priming phrase immediately preceded a target phrase. When a priming phrase was from the same story as its target phrase, responses to the target were facilitated. When a priming phrase was from another story of the same MOP as the target, responses were facilitated only if the test phrases were related to the MOP; there was no significant facilitation if the test phrases were not related to the MOP. In the case where the phrases were related to the MOP, there was as much facilitation when the phrases were from different stories as when they were from the same story. These results are shown to contradict previously proposed models of memory for script-like sequences, and a new, limited encoding, model is proposed. (o 1989 Academic Press, Inc.
\end{abstract}

Understanding how knowledge is represented is a central goal of both Cognitive Psychology and Artificial Intelligence. In the 1970s, one approach to this problem was the use of schemas to represent the structures of particular situations (Minsky's 1975 frames, Rumelhart's 1980 schemata, and Schank and Abelson's 1977 scripts). Schemas were intended to organize the temporal structures of stories or the spatial structures of visual scenes. For

Early stages of this research were significantly influenced by conversations with Bob Abelson at Yale. The research was supported by NSF Grant BNS 85 10361 to Roger Ratcliff, NIMH Grant MH 44640 to Roger Ratcliff, N1H Grant HD 18812 to Gail McKoon, and NSF Grant BNS 8616350 to Gail McKoon. Reprint requests should be sent to Gail McKoon, Psychology Department, Northwestern University, Evanston, IL 60208 . the reader of a story, a schema in memory would organize information as it was read, and it could also provide default values for specific actions or objects not presented explicitly in the story. With these default values, answers could be produced to questions asked after the story was read, even when the required information was not presented at input. In this way, schema theories were presented as a solution to some of the problems of inference.

As these models were developed, it soon became apparent that the original formulations of schemas were too rigid to provide a general solution to the problem of knowledge representation (Feldman, 1975; Schank, 1982). Knowledge structures need to be flexible; information to be encoded will not always fit an existing schema, so that modifications or conjunctions of exist- 
ing schemas need to be used. Or, when an inappropriate schema is initially used, then partially processed information should be available for the next try. Schank (1982) has also argued that the first implementations of scripts or schemas were too specific and did not support learning or generalization across schemas.

To overcome these kinds of problems, Schank (1982) has proposed a generalization of script theory, in which the units of analysis are called memory organization packets (MOPs). A MOP is a dynamically constructed structure that consists of a set of scenes directed towards the achievement of a goal. The MOP organizes the scenes, and the scenes contain specific information about actions. The "coloration" of a scene is the combination of general information about how actions in the scene are performed (e.g., how to pay) with the MOP context (e.g., paying the waitress at the table). The division between MOPs and scenes allows the information in scenes to be shared across MOPs.

The movement toward a more flexible conception of schemas has led directly to consideration of how information from a schema used for encoding in one situation can become available for encoding in a related situation (Schank, 1982). There are two obvious cases in which the need for cross retrieval of episodes arises. The first is when an incorrect schema is partially instantiated and some of the encoded information is needed for processing a new schema. The second is when information from one, previously instantiated, schema is used to guide understanding of a new set of information to be encoded with a similar schema. It is this second kind of cross retrieval of information that is the primary focus of the experiments in this article.

The experiments were designed to examine the cross retrieval of schematic information by examining the effect of cross retrieval on the representation of episodes in memory. Specifically, one result of cross retrieval, or "reminding," might be that an episode currently being processed is connected in memory to another retrieved episode. If one story led to retrieval of another story that was read earlier and shared the same MOP, then the two stories might be connected in memory, either directly or through the shared MOP.

Seifert, McKoon, Abelson, and Ratcliff (1986) tested for such connections between stories using pairs of stories that shared the same theme, rather than the same schema or MOP. For example, one story was about a graduate student who was treated badly and decided to leave for another school; his first school finally promised to treat him better, but the student had already enrolled elsewhere. The story that shared the same theme was about a secretary engaged to her boss; when the boss avoided setting a wedding date, the secretary went on to marry someone else, despite a last minute plea from the boss. These two stories share the theme of "closing the barn door after the horse has bolted." It might be predicted that if subjects read two stories with the same theme, then one story would remind them of the other, and the two stories would be connected together in memory (Schank, 1982; Dyer, 1983). To look for these connections, Seifert et al. (1986) used a priming task in which single sentences were presented for verification. On each trial of an experiment, two stories were presented for reading, and then a list of test sentences was presented. The responses of interest occurred in the case where a test sentence representing the resolution of one story was immediately preceded in the test list by a sentence representing the resolution of the other studied story. Priming (facilitation in response time and/or accuracy) should have occurred if the stories shared the same theme, and if reminding during reading connected the resolution of one to the resolution of the other. However, no priming was observed between the two resolutions, suggesting that reminding had not connected them together. Only when subjects were given specific instructions re- 
quiring ratings of thematic relatedness between the stories was priming obtained from one resolution to the other.

The conclusion drawn from the Seifert et al. (1986) results was that thematic relations between stories do not automatically lead to a reminding process that connects elements of one story to elements of another story. One possible explanation for the absence of connections is that reminding requires that stories have a greater amount of contextual semantic information in common than was the case in the stories used by Seifert et al. The experiments presented in this article were designed to extent the questions asked about thematic structures to stories that shared significant amounts of contextual semantic information. Whereas the stories used by Seifert et al. were based on general themes with intentionally dissimilar contexts (the grad student versus the secretary), the present studies used stories based on MOPs with overlapping information. In Table 1, the two stories share a MOP, going to the beach, and they also overlap almost com-

TABLE 1

MOP: GoING TO THE BEACH

First story

Linda decided to skip work on Thursday and go to the beach. At the beach, Linda found the parking lot to be surprisingly full for a weekday, but she eventually found a spot. The beach, too, was crowded, but Linda was still able to spread her towel in a dry place close to the water. Not wanting to get a sunburn, Linda put on some suntan lotion. After lying on her towel for some time, Linda was getting hot so she decided to take a dip, and dove into the refreshing water. After a short swim, Linda toweled off and packed up her things for the long walk to the car.

\section{Second story}

Because the sun was shining so brightly, Nancy decided to spend the day by the sea. When she had gotten to her favorite seaside spot, Nancy parked her car under a tree. Nancy walked quickly over the hot sand until she found an empty space where she could lay her blanket. Hoping to add some color to her pale skin, Nancy splashed on some baby oil. The sun was very strong, so Nancy decided to get up and go for a swim. Nancy slowly strolled out into the cool ocean. When she finally felt water-logged, she headed back to her blanket. She dried off for a while in the warm sun and then dressed for the trip home.

Test phrases for the second story

Condition 1, MOP-related prime from the same story

MOP-related prime: found an empty space for her blanket.

Target test phrase: slowly strolled out into the cool ocean.

Condition 2, MOP-related prime from the other story with the same MOP

MOP-related prime: spread her towel in a dry place.

Target test phrase: slowly strolled out into the cool ocean.

Condition 3, prime from another unrelated story:

Unrelated prime: looked over the wine list and ordered chablis.

Target test phrase: slowly strolled out into the cool occan.

Filler old (positive) test item

parked her car under a tree.

False test item

decided to spend the day at the lake.

Filler new (negative) test items

had not started the research on time.

eventually found some sources for the paper.

loaded the books into a heavy backpack. 
pletely in contextual semantic content. For example, in the context of going to the beach, putting on lotion and splashing on oil have a high degree of semantic overlap in the sense that the lexical items, while different, refer to the same action, and in the sense that they both refer to the same event (lubricate skin) in the going to the beach action sequence. The hypothesis motivating the experiments was that this contextual semantic overlap might support the establishment of connections or associations between the stories. The experiments were designed to look for evidence of such associations by looking for priming between actions of two stories that shared the same MOP. The procedure in the experiments was that subjects read a long list of stories, and then were given test phrases from those stories. This procedure is described in the next section, and a theoretical preview of the results is given in the following section.

\section{Experimental Design}

Through a series of five experiments, the general procedure was the same: A list of about 40 stories was followed by a list of about 200 test phrases. Subjects read the 40 stories one at a time, with each story followed by a single true/false test phrase (to keep the subjects attentive). The test items were phrases that expressed predicates only, rather than full sentences, so that subjects would not devote excessive attention to memorizing the names of all the characters that appeared in the 40 stories. Among the 40 stories were pairs that shared the same MOP; the two stories of a pair were separated by at least 8 other unrelated stories so that any observed reminding effects would be relatively long range. The 200 test items at the end of the experiment included phrases from the stories that were read (old items) and phrases from stories that the subjects had never read (new items); the subjects were instructed to decide whether each item was old or new.

The test items of interest for the experi- mental designs were old items from the stories the subjects had read. An item from one story of a MOP pair was designated the target. In some conditions, the immediately preceding test phrase, the prime, was from the same story and so should facilitate the response to the target. This facilitation would serve as a control to show that priming effects could be obtained with this procedure. In other conditions, the prime phrase was from a completely unrelated story and should not facilitate responses. The interesting conditions were those in which the prime phrase was from the other story of the same MOP. In Experiments 1 through 5, different questions were asked about possible facilitation effects from this prime phrase.

The experiments were designed to use the amount of priming in recognition as a dependent variable, so that the results would reflect associations that were established in memory at the time of reading the stories, rather than associations that were constructed at the time of the retrieval test. We know that subjects can generate such constructions; given a cue from one of the stories and enough time, subjects could generate the appropriate associations even if they had not noticed the relations between the two stories when they were studied (cf. Seifert \& Black, 1983). We have argued that the speeded item recognition procedure avoids such constructions at the time of the retrieval test (cf. Ratcliff \& McKoon, 1978, 1981; McKoon \& Ratcliff, 1981, 1986, 1989c, 1989d). With speeded recognition, subjects do not have time to generate new associations. Also, with a large number of test items that appear unrelated, there is no reason for the subjects to adopt strategies to generate one kind of association (the connections between stories) over another. That subjects did not, in fact, adopt such strategies in the experiments below is demonstrated through the use of pairs of new test phrases that were related to the same MOP. A strategy of relying on the MOP relation between the 
phrases of a pair instead of on memory for the stories would lead to fast errors on these phrases (responding old when the phrases were actually new), but such errors did not occur.

\section{Theoretical Preview}

The plan across the experiments was to investigate associations in memory between two stories of the same MOP. Some experiments were designed to look for associations between phrases that were related to the MOP. For example in Table 1, slowly strolled into the ocean is related to the Going to the Beach MOP, and so is spread her towel in a dry place. These phrases might be associated with each other in memory either directly, because they themselves are associated with the same MOP, or indirectly because they are in stories that express the same MOP. Other experiments were designed to look for associations between MOP-unrelated phrases, such as decided to skip work on Thursday. This phrase could be associated to slowly strolled into the ocean only indirectly, by virtue of being in a story that shared the same MOP.

Among models proposed to account for various findings about memory for MOP information, the one most relevant to the experiments in this article is the "partial encoding" model proposed by Bower, Black, and Turner (1970). According to this model, MOP stories are stored separately in memory. The explicitly stated events of a story are encoded into a new structure in memory, which is marked as an instance of the appropriate MOP. In addition to the new structure, in the generic representation of the MOP, both stated and unstated MOP actions are tagged. What would be predicted from this model is that two test phrases from the same story would prime each other more than two phrases from different stories, even if the two stories shared the same MOP. This is not what is shown by the data from the experiments in this article. Experiment 1 shows essentially "perfect priming"; a target phrase of one story is facilitated as much by a phrase from another story of the same MOP as by a phrase from the same story, if the target and priming phrases are both related to the MOP. It might also be expected from the Bower, Black, and Turner (1970) model that, if two stories were related by the same MOP, then any phrase from one of the stories would prime any phrase from the other story through the MOP connections. Again, this is not what the data show; in Experiments 2 and 3 there is no significant priming from a phrase of one story to a phrase from a different story of the same MOP, if the target phrase is not related to the MOP. To encompass this whole pattern of results, a new model is proposed in the General Discussion section of this article.

\section{EXPERIMENT 1}

The main question in Experiment 1 was whether a MOP-related phrase from one story would facilitate responses to a MOP. related phrase from another story with the same MOP. The procedure followed the general procedure described above: a list of 42 stories to be read followed by a list of 216 test phrases. Prime-target pairs of phrases were embedded in the test list to represent the experimental conditions. An example of the materials is shown in Table 1. The two stories are both about going to the beach, and the individual events in the two stories parallel each other closely.

The three conditions in the experiment are reflected in the test phrases shown for the second story. The target test phrase is the same in each condition, a phrase clearly and centrally related to the MOP. In the first condition, this phrase is primed by another MOP-related phrase from the same story; in the second condition, by a MOPrelated phrase from the other story of the same MOP; and in the third condition, by a phrase from some other unrelated story. Facilitation would be expected in the first condition (the within-story condition) relative to the third condition (the between- 
MOP condition). The question was whether there would also be facilitation in the second condition (within-MOP, but betweenstories) relative to the third. If there were associations in memory between the events of the two stories, then there should be such facilitation.

In the first and second conditions just described, the prime and target phrases are related to the same MOP. So that subjects would not be able to respond old to the target on the basis of this relationship alone, related pairs of new test phrases were included in the test list. These were phrases taken from stories like the stories that were studied by the subjects except that they were based on different MOPs than any of the studied stories (see examples in Table 1). With these related new pairs included in the test list, a MOP relationship between one test phrase and an immediately following test phrase could not be used to decide whether the second phrase was old or new.

Previous research provides two predictions about the outcome of Experiment 1. In the Seifert et al. (1986) study using thematic relations between stories, a test statement from one story did not facilitate responses to a test statement from another, thematically similar story. If MOP similarity operated in the same way as thematic similarity, then there would be no facilitation between test phrases from stories of the same MOP. A different outcome would be predicted from consideration of the information shared by the test phrases in the experimental conditions. In the first condition, the prime phrase and the target phrase share the same MOP and they come from the same story. It would be reasonable to predict that this condition would lead to more facilitation than the second condition, in which the prime and target share only MOP information (cf. Bower, Black, \& Turner, 1979).

\section{Method}

Subjects. The 24 subjects participated in the experiment for credit in an introductory psychology course. Each subject participated in one session lasting about $50 \mathrm{~min}$.

Materials. Twenty-one pairs of stories were written, each pair representing a different MOP. Examples are shown in Table 1 . The stories described the events of a typical instance of the MOP. There was no plot to the stories other than the standard MOP action sequence, and none of the events was surprising in the context of the MOP. The two stories of each MOP pair had parallel structures and events, but differed in specific details. For example, in the restaurant MOP, both stories described a fairly expensive, formal type of restaurant, one French and one Italian. Both meals included a dessert typical of such a meal, one chocolate mousse and one creme caramel. As can be seen in the examples, content words from one story of a pair were repeated as rarely as possible in the other story of the pair. The stories averaged 108 words in length.

For each story, there were five test phrases. Each phrase was formed from a sentence that had a main character or characters of the story as subject, and then had this subject deleted to form a predicate phrase. This form of test was used because we had found in pilot work that when test sentences included the names of the characters, subjects became extremely concerned about memorizing the names of all the characters, and response times were slow and highly variable. Two phrases, one designated the target and the other the MOP prime, represented events closely related to the MOP of the story; these are shown in the Appendix. These test phrases were parallel for the two stories of a pair in that they represented corresponding events. Another test phrase was also used as a prime, but was not specifically related to the MOP. Finally, there were two filler test phrases, which were not controlled with respect to relation to the MOP. The correct response for the first four test phrases was true or old, and for the last filler, the correct response was false. The 
average length of the target phrases was 7.8 words, and the average length of the prime phrases was 8.3 words.

In addition to the MOP stories and their test phrases, there was a pool of phrases to be used as new (negative) test items in the final test. These test phrases came from stories other than those read by the subjects and concerned MOPs that were not used in any of the stories the subjects read. In other respects, the test phrases were similar to the ones used for the 42 MOP stories.

Procedure. Materials were presented on CRT screens, and responses were collected on the CRT keyboards. The CRTs were controlled by a real-time microcomputer system.

The experiment began with practice stories and test phrases. First, a series of six stories was presented, each followed by a single truelfalse test phrase. Then there was a list of 20 test phrases over all six stories. Subjects were instructed that, for a test phrase immediately following a story, they were to decide whether it was true or false according to the story. For the list of 20 test phrases, they were told that the positive phrases would be phrases true according to one of the six stories and that negative phrases would be phrases that were not at all related to any of the six stories. They were told that in this list there would be no false phrases related to any of the stories. Subjects were also told the form of the test phrases (predicates), and it was explained that this form of test item meant that they would not have to be concerned about memorizing character names or trying to keep track of which character did what.

After the practice, subjects were told the form of the experiment proper: 42 stories, each followed by a true/false test phrase, and a final list of 216 test phrases. Each story began with an instruction presented on the CRT screen to press the space bar of the keyboard to initiate the story. Then the story was displayed for $22 \mathrm{~s}$, the screen was cleared, there was $1 \mathrm{~s}$ pause, and the true/ false test item was displayed. The phrase remained on the screen until the subject pressed a response key ("?/" for true; " $\mathrm{Z}$ " for false). If the response was correct, then the instruction to press the space bar for the next story was displayed. If the response was incorrect, the word ERROR was displayed for $2 \mathrm{~s}$ before the instruction to press the space bar. The $22 \mathrm{~s}$ reading time was chosen from pilot work; it allowed all subjects to read the stories completely at a comfortably slow rate.

After the last story and its test phrase, the words FINAL TEST were shown for 10 $\mathrm{s}$, and then the list of final test phrases began. Each phrase was displayed until the subject made a response, old or new. Error feedback was given in the same way as for the test phrases following stories, and then the next test phrase appeared after $100 \mathrm{~ms}$.

The 42 stories were presented in random order, except that the two stories of a pair were separated by at least 8 other stories. The final list of 216 test phrases was made up of 126 positive phrases and 90 negative phrases. Of the 126 positive phrases, 42 were target phrases and each of these was immediately preceded by a positive priming phrase. The other 42 positive items were fillers from the studied stories. Some of the 90 negative test phrases were presented as related pairs, so that one negative test phrase would be followed by another negative test phrase related to the same MOP. On the average (across subjects), there were 27 such pairs and 36 other negative phrases. Test phrases were presented in random order, except that targets could not be among the first 15 test phrases, and a filler positive phrase could not appear in the three positions preceding the target from the same story.

Design. A target phrase from a story was immediately preceded in the final test list by another phrase from the same story (the MOP-related prime), a phrase from the other story of the same MOP (also a MOPrelated prime), or a phrase from another story about a different MOP (a prime not 
specifically related to a MOP). These three conditions were combined with groups of subjects (eight per group) and sets of stories (14 per set) in a Latin square design.

\section{Results}

Means were calculated for each subject and test phrase in each condition; only responses for which responses to the preceding test phrase were correct were included in these means. The means show that the response to a target test phrase was facilitated as much by a priming phrase from a different story with the same MOP as by a priming phrase from the same story. When a target was primed by another phrase from the same story, the mean response time was $1287 \mathrm{~ms}$ (10\% errors). The mean was $1283 \mathrm{~ms}$ ( $11 \%$ errors), when the prime was a phrase from the other story of the MOP pair. When the prime was from a completely unrelated story, the mean response time was $1417 \mathrm{~ms}$ (17\% errors). The difference among the response time means was significant with subjects as a random variable, $F(2,46)=5.08(p<.05$ throughout this article), and with test phrases as a random variable, $F(2,82)=3.82$. The difference among error rates was also significant, $F(2,46)=3.63$ with subjects as the random variable and $F(2,82)=6.11$ with test phrases as the random variable. The standard error of the response times was $29.6 \mathrm{~ms}$.

For the test phrases that immediately followed the stories during the reading phase of the experiment, the average response time for true test phrases was $1653 \mathrm{~ms}$ (15\% errors), and the average for false test phrases was $1672 \mathrm{~ms}$ (13\% errors). On final test phrases other than targets, positive responses averaged $1378 \mathrm{~ms}$ (18\% errors). The mean for negative responses that did not immediately follow another related negative phrase was $1484 \mathrm{~ms}$ ( $9 \%$ errors) and the mean for negative test phrases that followed related negative test phrases was $1472 \mathrm{~ms}$ (17\% errors); both of these means represent responses for which there was a correct negative response on the previous test item. This indication of a speed/ accuracy trade-off for the negatives will be observed in all of the following experiments. This trade-off might indicate that subjects were using the relational information to speed up their responses, and as a result they made more errors on the negative phrases that followed related negative phrases. However, this was not the case because the error reaction times were actually very slow, $1622 \mathrm{~ms}$ and $1588 \mathrm{~ms}$, respectively. Furthermore, for the related negative test items, the distributions of the responses faster than the mean for correct and error response times were about the same, so the errors do not represent a probability mixture of fast guesses based on relatedness and other, slow responses (this check of the distributions was done for this experiment and for Experiment 3). These results for negatives show that a simple strategy of using relational information to speed responses could not account for the facilitation effects observed with positive responses.

\section{Discussion}

The results of Experiment 1 support the idea that, when two stories share a MOP, MOP-related phrases from the two different stories are just as closely associated as MOP-related phrases from the same story. Spreading out her towel in a dry place from one story and found an empty space for her blanket from the other story appear to be equally good primes for slowly strolled into the cool ocean.

It should be noted that the facilitation given by a MOP-related priming phrase to a MOP-related target cannot be due to simple and direct semantic associations between the individual words of the prime and target phrases. Most of the prime-target pairs do not contain direct associates (see the Appendix), and work by de Groot (1983), Balota and Lorch (1986), and McNamara and Altarriba (1988) has shown that, in lexical decision, the range of priming is only to 
close associates, and not further to the range of associates that would be required to account for the results of Experiment 1.

Experiment 1 shows that there is equally good facilitation on a target from a different story of the same MOP as from the same story. The question immediately raised is whether the facilitation is a consequence of the MOP structure shared by the information in the test phrases, or whether it extends to all information present in the stories. This question was addressed in Experiment 2 by examining facilitation for test phrases not related to the MOPs of their stories.

\section{EXPERIMENT 2}

In Experiment 2, the question was whether a priming phrasc from a story of a MOP pair would give facilitation to a target phrase from the other story of the pair when the information in the target phrase was not related to the MOP. The design was the same as in Experiment 1 except that the target phrases were changed so that they were not related to the MOPs of their stories. To provide these phrases, new information was added to each story; this information fit in logically with the story, but was in no way related to the MOP. For example, as shown in Table 2, new information in one story of the Going to the Beach MOP was that the main character usually enjoyed the power of her executive secretary position, and new information in the other story was that the main character watched the cliffs above her for nesting swallows.

\section{Method}

The main difference between Experiments 1 and 2 was that in Experiment 2, each story was changed by the addition of one piece of information that was not related to the MOP (see Table 2). This information was used to form the MOPunrelated target test phrase for the story. The prime phrase was the same as that used in Experiment 1. In all other respects, the materials, procedure, and design were the same as in Experiment 1. There were 30 subjects from the same population as Experiment 1 .

\section{Results}

In contrast to Experiment 1, responses to target test phrases were facilitated significantly only when the priming phrase was from the same story. Mean response times to a target were $1291 \mathrm{~ms}$ ( $16 \%$ errors) when the prime was from the same story as the target. When the prime was from the other story of the same MOP as the target, the mean response time was $1351 \mathrm{~ms}(19 \%$ errors), not much different than when the prime was from an unrelated story, $1360 \mathrm{~ms}$ (22\% errors). Overall, the mean response times differed significant, $F(2,58)=5.20$ with subjects as the random variable, and $F(2,78)=3.11$ with test phrases as the random variable. Standard error of the response time means was $18.3 \mathrm{~ms}$. The differences among crror ratcs were not significant, $F$ 's $<1.85$.

In the final test list, responses on positive fillers averaged 1309 ms (15\% errors). Responses on negative fillers averaged 1442 ms ( $14 \%$ errors, $1522 \mathrm{~ms}$ error RTs), and responses on the negative fillers that were preceded by related negative fillers averaged $1420 \mathrm{~ms}$ ( $20 \%$ errors, $1400 \mathrm{~ms}$ error RTs); in both cases, the means are for responses that were preceded by a correct negative response. For test phrases presented during the reading phase, the means were $1506 \mathrm{~ms}$ (17\% errors) for true items and $1619 \mathrm{~ms}$ (11\% errors) for false items.

\section{Discussion}

The result of Experiment 1 shows that MOP-related information from one story is closely associated to MOP-related information from another story that shares the same MOP. Experiment 2 shows that this result does not extend to MOP-unrelated information. MOP-unrelated information appears to be associated to other information in its story, but not to information from 
TABLE 2

MOP: GOING TO THE BEACH

\begin{abstract}
Story 1
Linda decided to skip work on Thursday and go to the beach. $\Lambda t$ the beach, Linda found the parking lot to be surprisingly full for a weekday, but she eventually found a spot. The beach, too, was crowded, but Linda was still able to spread her towel in a dry place close to the water. Not wanting to get a sunburn, Linda put on some suntan lotion. After lying on her towel for some time, Linda was getting hot so she decided to take a dip, and dove into the refreshing water. Although she usually enjoyed the power of her executive secretary position, today she was happy not to be at work. After a short swim, Linda toweled off and packed up her things for the long walk to the car.
\end{abstract}

Story 2

Because the sun was shining so brightly, Nancy decided to spend the day by the sea. When she had gotten to her favorite seaside spot, Nancy parked her car under a tree. Nancy walked quickly over the hot sand until she found an empty space where she could lay her blanket. Hoping to add some color to her pale skin, Nancy splashed on some baby oil. The sun was very strong, so Nancy decided to get up and go for a swim. Nancy slowly strolled out into the cool ocean. Her hobby was bird-watching, so she watched the cliffs above her for nesting swallows. When she finally felt water-logged, she headed back to her blanket. She dried off for a while in the warm sun and then dressed for the trip home.

\author{
Test phrases for the second story \\ Condition 1, MOP-related prime from the same story \\ MOP-related prime: found an empty space for her blanket. \\ Target test phrase: watched the cliffs above for nesting swallows. \\ Condition 2, MOP-related prime from the other story with the same MOP \\ MOP-related prime: spread her towel in a dry place. \\ Target test phrase: watched the cliffs above for nesting swallows. \\ Condition 3, prime from another unrelated story \\ Unrelated prime: looked over the wine list and ordered chablis. \\ Target test phrase: watched the cliffs above for nesting swallows. \\ Filler old (positive) test item \\ parked her car under a tree. \\ False test item \\ decided to spend the day at the lake. \\ Filler new (negative) test items \\ had not started the research on time. \\ eventually found some sources for the paper. \\ loaded the books into a heavy backpack.
}

another story of the same MOP. These are the basic results that will be discussed in the General Discussion. Experiments 3, 4, and 5 rule out several alternative explanations of these results.

\section{EXPERIMENT 3}

In Experiment 1, a MOP-related prime gave equal facilitation to MOP-related targets from the same story as to MOP-related targets from a different story of the same
MOP. One explanation of this result that would make it uninteresting would be that the MOP-related phrases used for targets in the two stories are synonymous. For example, suppose that the target in one story was had creme caramel for a final course and the target in the other story was had caramel custard for dessert. These two phrases would be essentially synonymous, and so it would be no surprise to find that responses to either of them could be facilitated by a 
MOP-related prime from either story. Although the targets used in Experiment 1 (shown in the Appendix) were not so clearly synonymous as these examples, it is difficult to know how to evaluate synonymy in discourse contexts. Thus, Experiment 3 was conducted to rule out a synonymy explanation of the results of Experimont 1 .

Experiment 3 was identical to Experiment 2 in that the same stories and the same MOP-unrelated target were used. However, the prime phrases were changed to be the MOP-related phrases that were used as targets in Experiment 1. Thus, for the second story in Table 2, the target test phrase was watched the cliffs above for nesting swallows. Its priming phrase from the same story was slowly strolled out into the cool ocean and its priming phrase from the other story of the same MOP was dove into the refreshing water.

The reasoning behind Experiment 3 was that, if the two priming phrases (used as targets in Experiment 1) were synonymous, then they should facilitate responses to the target equally well. Watched the cliffs for nesting swallows should be facilitated equally well by the prime from the same story as by the prime from the other story of the same MOP. Although the two priming phrases do not appear to be exactly synonymous, in their story contexts they may be close enough to synonymy to give statistically equivalent amounts of facilitation to the target. Alternatively, if the two priming phrases are not synonymous even in their story contexts, then the prime from the same story should give more facilitation to the target. This result would replicate the result of Experiment 2, where the MOPrelated prime from the same story gave more facilitation to a MOP-unrelated target.

\section{Method}

The stories, test phrases, and procedure were all the same as in Experiment 2. The same MOP-unrelated phrases were used as targets. The only difference from Experiment 2 was that the MOP-related targets from Experiment 1 were used as primes. There were three experimental conditions: the prime for the MOP-unrelated target was from the same story, from a different story of the same MOP, or from a completely unrelated story. There were 57 subjects from the samc population as Experiment 1. This large number of subjects was used because average target response times were somewhat faster with a prime from another story of the same MOP than with a prime from an unrelated story; however, this difference never reached even marginal statistical significance.

\section{Results}

If the two MOP-related phrases used as primes did not function as though they were synonymous, then the results should replicate the results of Experiment 2. A MOPunrelated target should be facilitated more by a priming phrase from the same story than by a priming phrase from a different story of the same MOP, and a priming phrase from a different story of the same MOP should give no more facilitation than a priming phrase from an unrelated story. This is the result that obtained. Response times for the targets were faster with the prime from the same story than with the prime from the other story of the same MOP. The average response times were $1467 \mathrm{~ms}$ (18\% errors) and $1530 \mathrm{~ms}(22 \%$ errors), respectively. With the prime from an unrelated story, the mean response time was $1573 \mathrm{~ms}$ ( $25 \%$ errors). Overall, the response time means differed significantly, $F(2,112)=7.7$ with subjects as the random variable and $F(2,82)=3.6$ with items as the random variable. Although response times in the condition with the prime from another story of the same MOP were faster than response times in the condition with an unrelated prime, this difference was not significant, $F$ 's $<1.6$. The standard error for the response time means was $20.7 \mathrm{~ms}$. Differences in error rates were significant, 
$F(2,112)=6.04$ with subjects as the random variable and $F(2,82)=5.4$ with items as the random variable.

In the final test list, responses on positive fillers averaged $1563 \mathrm{~ms}$ (17\% errors). Responses on negative fillers averaged 1742 ms ( $16 \%$ errors, $1974 \mathrm{~ms}$ error RTs), and responses on the negative fillers that were preceded by related negative fillers averaged $1663 \mathrm{~ms}$ ( $22 \%$ errors, $1688 \mathrm{~ms}$ error RTs); in both cases, the means are for responses that were preceded by a correct negative response. The distributions of response times faster than the means for correct and error responses to the related negatives were not different. For test phrases presented during the reading phase, the means were $1690 \mathrm{~ms}$ (14\% errors) for true items and $1882 \mathrm{~ms}$ (16\% errors) for false items.

\section{Discussion}

Experiment 3 was designed to test whether the results of Experiment 1 could be explained by the synonymy of the MOPrelated targets used in Experiment 1. If the targets were synonymous, then when they were used as primes, they should have given facilitation to target phrases from different stories of the same MOP. This did not occur, although there appeared to be some facilitation in the response time means, the effect was not even marginally significant. Instead, Experiment 3 replicated Experiment 2, in that MOP-related phrases gave significant facilitation only to MOP-unrelated phrases from the same story.

\section{EXPERIMENTS 4 AND 5}

Experiment 3 ruled out one possible explanation for the result of Experiment 1. Another possible explanation is that the associations between MOP-related events in different stories are due to semantic overlap between the individual phrases used as primes. The semantic overlap would not be direct, context-free associations, but contextual semantic overlap based on the gen- eral MOP structure. In other words, in the context of the MOP about going to the beach, finding a place for a blanket is not very different from spreading a towel, and it may be this similarity between the specific phrases used as primes rather than the similarity between the stories as a whole that accounts for the facilitation obtained in Experiment 1.

There is also an alternative explanation of the results of Experiment 2. It might be that the similarity between the primes causes subjects to have problems in discriminating whether a test phrase appeared in one or the other of the two possible stories with the same MOP. This discrimination problem might have covered up a real facilitation effect in Experiment 2 when a MOP-unrelated target was primed by a phrase from the other story of the same MOP. (This problem would also have reduced the amount of facilitation that was actually observed in Experiment 1.)

These two possible alternative explanations, one for the results of Experiment 1 and one for the results of Experiment 2, were examined in Experiments 4 and 5 using a condition in which the priming phrase from one story did not have a parallel in the other story of the same MOP (see Table 3 ). In this condition (Condition 2 in Table 3), the target was primed by a MOP-related phrase from the other story with the same MOP, but there was no parallel phrase in the story of the target. In Condition 1 , there was such a phrase, as there had been in Experiments 1 and 2 . Condition 3 was the same as in the previous experiments, a prime from a story unrelated to the target.

In Experiment 4, the targets were MOPrelated (as shown in Table 3 ). If the facilitation on these targets from a phrase from another story of the same MOP was due to the specific similarity between individual phrases and not to overlap between the whole stories, then the facilitation effect should disappear in Condition 2 of Experiment 3 . It should be stressed that the experiment only tests for the effect of the 
TABLE 3

MUP: GOING TO THE BEACH

Story 1

Linda decided to skip work on Thursday and go to the beach. At the beach, Linda found the parking lot to be surprisingly full for a weekday, but she eventually found a spot. The beach, too, was crowded, but Linda was still able to spread her towel in a dry place close to the water. Not wanting to get a sunburn, Linda put on some suntan lotion. After lying on her towel for some time, Linda was getting hot so she decided to take a dip, and dove into the refreshing water. Although she usually enjoyed the power of her executive secretary position, today she was happy not to be at work. After a short swim, Linda toweled off and packed up her things for the long walk to the car.

Story 2, with phrase corresponding to priming phrase in Story 1

Because the sun was shining so brightly, Nancy decided to spend the day by the sea. When she had gotten to her favorite seaside spot, Nancy parked her car under a tree. Nancy walked quickly over the hot sand until she found an empty space where she could lay her blanket. Hoping to add some color to her pale skin, Nancy splashed on some baby oil. The sun was very strong, so Nancy decided to get up and go for a swim. Nancy slowly strolled out into the cool ocean. Her hobby was bird-watching, so she watched the cliffs above her for nesting swallows. When she finally felt water-logged, she headed back to her blanket. She dried off for a while in the warm sun and then dressed for the trip home.

Story 2, without phrase corresponding to priming phrase in Story 1

Because the sun was shining so brightly, Nancy decided to spend the day by the sea. When she had gotten to her favorite seaside spot, Nancy parked her car under a tree. Nancy walked quickly over the hot sand. Hoping to add some color to her pale skin, Nancy splashed on some baby oil. The sun was very strong, so Nancy decided to get up and go for a swim. Nancy slowly strolled out into the cool ocean. Her hobby was bird-watching, so she watched the cliffs above her for nesting swallows. When she finally felt water-logged, she headed back to her blanket. She dried off for a while in the warm sun and then dressed for the trip home.

\section{Test phrases for the second story}

Condition 1, MOP-related prime from Story 1, study Stories 1 and 2a

MOP-related prime: spread her towel in a dry place

Target test phrase: slowly strolled out into the cool ocean.

Condition 2, MOP-related prime from Story 1, study Stories 1 and 2b

MOP-related prime: spread her towel in a dry place.

Target test phrase: slowly strolled out into the cool ocean.

Condition 3, prime from another unrelated story:

Unrelated prime: looked over the wine list and ordered chablis.

Target test phrase: slowly strolled out into the cool ocean.

presence or absence of an explicitly stated parallel phrasc. It might be that subjects would infer the phrase when it was not stated explicitly. However, it seems unlikely that subjects could infer the phrase so exactly that it would function in the same way as if it had been explicitly stated (cf. McKoon \& Ratcliff, 1989a, 1989b, 1989d).

In Experiment 5, the targets were MOPunrelated as in Experiment 2. If the lack of facilitation on these targets from a phrase from another story of the same MOP was due to the kind of discrimination problems mentioned above, then these problems should disappear when there is no overlap between individual phrases, and facilitation might appear in this condition.

\section{Method}

Subjects. There were 40 subjects in $\mathrm{Ex}^{-}$ periment 4 and 33 subjects in Experiment 5 , all from the same population as Experiment 1.

Materials and Procedure. For each of the 
stories used in Experiment 2, a new version of the story was formed by deleting from the original story the information that corresponded to the MOP-related prime in the other story of the pair. For example, in Table 3 , the priming phrase from Story 1 is spread her towel in a dry place, and the parallel phrase in the target story is found an empty space for her blanket. This phrase was present in the first version of Story 2 , and deleted in the second version.

All of the test phrases remained the same as in Experiments 1 and 2, and the procedure for testing was the same as in Experiments 1 and 2.

Design. In the first two conditions, the target phrase for a story was primed by a MOP-related prime from the other story of its pair. In Condition 1, the phrase corresponding to the prime was present in the target's story, and in Condition 2, the corresponding phrase was not present in the target's story. In Condition 3, the prime for the target was from a completely unrelated story. In Experiment 4, the target itself was related to the MOP of its story, while in Experiment 5, the target was not related to the MOP.

\section{Results}

In Experiment 4, responses to the MOPrelated targets were facilitated equally well by the MOP-related primes in Conditions 1 and 2 . That is, it did not matter that in Condition 2 , the phrase equivalent to the priming phrase was missing from the target's story. The mean response time in Condition 1 , when the phrase equivalent to the priming phrase was in the target's story, was $1402 \mathrm{~ms}$ (11\% errors); in Condition 2, the mean was actually a little faster, $1373 \mathrm{~ms}$ (11\% errors). In the third condition, where the prime was from a story unrelated to the target's story, mean response time was $1486 \mathrm{~ms}$ (18\% errors). Differences among the response time means were significant, $F(2,78)=11.76$ with subjects as the random variable, and $F(2,82)=17.32$ with items as the random variable. Post hoc tests showed the difference between conditions 1 and 2 was not significant, $F$ 's $<1.3$. Differences in error rates were significant, $F(2,78)=4.1$ with subjects as the random variable, and $F(2,82)=2.73$ (marginally significant) with items as the random variable. The standard error for the mean response times was $18 \mathrm{~ms}$.

On filler test phrases, the mean for positive responses was $1481 \mathrm{~ms}$ (18\% errors). For single negative phrases, the mean was $1617 \mathrm{~ms}$ (9\% errors, $1697 \mathrm{~ms}$ error RTs), and for negative phrases immediately following related negative phrases, $1583 \mathrm{~ms}$ ( $21 \%$ errors, $1652 \mathrm{~ms}$ error RTs), in both cases conditionalized on a correct response to an immediately preceding negative test item. On the test phrases that followed stories during the reading phase, the mean for true phrases was $1628 \mathrm{~ms}$ ( $8 \%$ errors) and the mean for false phrases was $1757 \mathrm{~ms}(9 \%$ errors).

In Experiment 2, when targets were MOP-unrelated, there was no apparent priming between stories with the same MOP. This result did not change in Experiment 5 when the phrase corresponding to the MOP-related prime was removed from the target story. Mean response times did not differ significantly across experimental conditions $(F$ 's $<1.2)$. The means for Conditions 1,2 , and 3 were: 1457 ms $(21 \%$ errors), $1417 \mathrm{~ms}$ ( $17 \%$ errors), and $1465 \mathrm{~ms}$ ( $25 \%$ errors). The standard error for the response times was $18 \mathrm{~ms}$. The differences in error rates were significant by subjects but not items; $F(2,64)=5.7(p<.01)$ with subjects as the random variable, and $F(2,82)=$ $2.3(p>.10)$ with items as the random variable. This effect on errors might indicate that Condition 2 , in which priming phrases wcre not present in the target story, led to slightly better discrimination, as discussed in the introduction to the experiment. But the effect is not significant with items so no firm conclusions can be drawn.

For filler positive test items, mean response times were $1422 \mathrm{~ms}$ (16\% errors). For single negatives, the mean was $1525 \mathrm{~ms}$ 
( $12 \%$ errors; $1619 \mathrm{~ms}$ error RTs), and for negatives that followed related negatives, the mean was $1488 \mathrm{~ms}$ ( $21 \%$ errors, $1642 \mathrm{~ms}$ error RTs), both conditionalized on a correct negative response to the previous test item. For true phrases that immediately followed stories, responses averaged $1474 \mathrm{~ms}$ (12\% errors), and for false phrases, $1707 \mathrm{~ms}$ (12\% errors).

\section{Discussion}

The results of Experiment 4 show that the facilitation observed in Experiment 1 is not due to repetition of specific action phrases in the two stories of the same MOP. Instead, it appears that the overall MOP similarity of the two stories accounts for the facilitation effect for MOP-related itcms. In addition, Expcriment 5 rcplicated Experiment 2, in that the MOP relationship did not produce any facilitation when the test items were unrelated to the MOPs. Therefore, relations between specific actions in the priming items of the two stories did not determine the results of Experiments 1 and 2 .

\section{EXPERIMENT 6}

Onc way to describe the results of Expcriments 1 and 4 would be to say that subjects cannot discriminate whether two MOPrelated phrases were from the same or different stories. For such phrases, a prime from the other story with the same MOP gives just as much facilitation as a prime from the same story. However, in Experiments 1 and 4, facilitation was measured with a speeded recognition task, and subjects were not explicitly required to discriminate between stories. Experiment 6 used a different task, forced choice recognition, that did require subjects to explicitly decide whether a test phrase belonged to a particular story that they had read.

In Experiment 6, subjects read stories following the same procedure as in the other experiments. This procedure included the same practice with six stories followed by their final list of 20 test phrases. But the final test list that followed the 40 experimental stories was different. For each item in the list, the first four lines of one of the studied stories were presented, followed by two test phrases. A subject's task was to decide which of the two phrases had appeared in the story that began with the four lines. It was always the case that both phrases had appeared in one of the studied stories. An example of the conditions in Experiment 6 is shown in Table 4 . Because the procedure was exactly the same in Experiment 6 as in the other cxperiments up to the point of the final test, it can be assumed that subjects learned the stories in the same way as for the other experiments. From the practice, they expected the same kind of final test, and they were instructed about the choice task only after all stories had been read.

For MOP-related test phrases, in Condition 1 , the incorrect choice was from the other story of the same MOP. If subjects' performance is better than chance in Condition 1, then it can be concluded that subjects can discriminate which MOP-related phrase goes with which of the two MOP stories. In Condition 2, the choice is between a test phrase that clcarly fits the MOP of the four story lines and a test phrase that is completely MOP-unrelated. Condition 2 was included in the experiment so that there would be one condition in which subjects could be sure of their choices; whether they rely on memory or guessing, they should be able to make the correct choice.

For MOP-unrelated test phrases, in Condition 3, the incorrect choice was from the other story with the same MOP as the four story lines. Neither test phrase was related to the MOP, so that correct discrimination should depend on memory for the studied story. In Condition 4, the incorrect choice was from a story completely unrelated to the four story lines, and again successful discrimination should depend on memory for the story as it was studied.

In all of the conditions of Experiment 6, 
TABLE 4

EXAMPLES OF EXPERIMENTAL CONDITIONS IN EXPERIMENT 5

Condition 1, MOP-related test phrases from stories of the same MOP

Linda decided to skip work on Thursday and go to the beach. At the beach, Linda found the parking lot to be surprisingly full for a weekday, but she eventually found a spot. The beach, too, was crowded, but Linda was still able to spread her towel in a dry place close to slowly strolled out into the cool ocean. dove into the refreshing water. (the correct choice)

\section{Condition 2, MOP-related test phrases from stories of different MOPS}

Linda decided to skip work on Thursday and go to the beach. At the beach, Linda found the parking lot to be surprisingly full for a weekday, but she eventually found a spot. The beach, too, was crowded, but Linda was still able to spread her towel in a dry place close to

looked over the wine list and ordered chablis.

dove into the refreshing water. (the correct choice)

\section{Condition 3, MOP-unrelated test phrases from stories of the same MOP}

Linda decided to skip work on Thursday and go to the beach. At the beach, Linda found the parking lot to be surprisingly full for a weekday, but she eventually found a spot. The beach, too, was crowded, but Linda was still able to spread her towel in a dry place close to watched the cliffs above for nesting swallows.

enjoyed the power of her executive secretary position. (the correct choice)

\section{Condition 4, MOP-unrelated test phrases from stories of different MOPS}

Linda decided to skip work on Thursday and go to the beach. At the beach, Linda found the parking lot to be surprisingly full for a weekday, but she eventually found a spot. The beach, too, was crowded, but Linda was still able to spread her towel in a dry place close to

was coming down with a cold and fever.

enjoyed the power of her executive secretary position. (the correct choice)

discriminative information from memory may be disregarded by subjects in favor of other information generated at the time of the forced choice test. For example, one of the test phrases may fit with the four story lines better than the second, even when the second is the correct choice. To measure performance based on this kind of information, a second group of subjects was given only the test phase of the experiment; they never read the stories. These subjects provided a control against which performance of subjects who read the stories could be measured. If the subjects who read the stories show better discrimination than the control subjects, then it can be concluded that they have some discriminative information in memory. However, if their performance is not better, then it may be that they are using the same kind of information as the control subjects and ignoring information from memory for the stories. So re- sults showing performance no better than the control subjects will not allow the conclusion that memory contains no discriminating information. Rather, it might be that subjects who read the stories disregarded whatever discriminating information was available in memory in favor of information available in the forced choiced task.

\section{Method}

Subjects. There were 24 subjects from the same population as the previous experiments.

Materials. Twenty of the pairs of stories from Experiments 1 and 2 were used. The true/false test phrases that immediately followed the stories were also the same as in Experiments 1 and 2. For the final test, the test phrases were either the MOP-related targets or the MOP-unrelated targets, the same phrases as were used in the previous experiments. 
Procedure. The procedures for practice and for reading the stories (each story with one immediately following true/false test phrase) were the same as in the previous experiments. The final test phase began with instructions; subjects were told that they would be given the first four lines of each story, plus two test phrases. They were to decide which of the two test phrases had actually appeared in the story indicated by the four lines. Each test item began with a message on the CRT screen to press the space bar of the keyboard. Then the four lines of the story and the two test phrases were presented simultaneously, with the test phrases separated from the story and each other by blank lines. The subjects pressed the "?/" key to indicate that the first of the test phrases was the correct choice, and the " $Z$ ' key to indicate that the second was the correct choice. If the response was incorrect, the word ERROR was displayed for $2 \mathrm{~s}$. Then the message to press the space bar was displayed for the next test item. The 40 test items, one per story, were presented in random order, and the position of the correct test phrase (first or second) was chosen randomly.

Design. The two test phrases for a story were either both MOP-related or both MOP-unrelated, with respect to the story in which they had appeared during study. The test phrase that was the wrong choice was either from the other story of the same MOP as the correct choice, or from some unrelated story. These four conditions were combined in a Latin square design with four groups of subject (six per group) and four sets of stories (10 per set).

Control subjects. A second group of 16 subjects was used to provide a control. They did not read the $\mathbf{4 0}$ stories and were given only a final test list (constructed by the same design as for the other subjects). They were told to guess as well as they could which of the two test phrases would have been in a story that began with the four story lines.

\section{Results}

For Conditions 1 and 2, with MOPrelated test phrases, subjects who read the stories did not do significantly better than the control subjects who did not read the stories. In Condition 1, subjects who read the stories were $63 \%$ correct and subjects who did not read the stories were $55 \%$ correct. In Condition 2, the corresponding figures were $90 \%$ and $98 \%$. In neither condition was the difference between the two groups of subjects larger than two standard errors (two standard errors equalled 9\%). While the difference in Condition 1 approached significance, the size of the difference was small in absolute terms.

For Conditions 3 and 4, with MOPunrelated test phrases, subjects who read the stories did do better. In Condition 3, with incorrect test phrases from the other story of the same MOP as the correct choices, performance was $69 \%$ correct for subjects who read the stories and $51 \%$ correct for subjects who did not. In Condition 4 , with incorrect test phrases from unrelated stories, correct performance was $83 \%$ and $69 \%$. In both Conditions, the differences are larger than two standard errors (as above, $9 \%$ ).

\section{Discussion}

With MOP-related test phrases, subjects' performance does not show significant discrimination; their performance does not show which of the two test phrases was actually studied in the same story as the four story lines given at test. However, as mentioned in the introduction to the experiment, this result does not allow the conclusion that memory contains no discriminating information. Instead, all that can be concluded is that whatever discriminating information there is must be weak enough that it can be ignored in favor of other information available at test time. If there is memory for discriminating information, it is disregarded and the test is completed using other information (e.g., general knowledge). 
With MOP-unrelated test phrases, subjects do show discrimination; their performance does show which of the two test phrases were studied in the same story as the four lines. This result parallels the result obtained in Experiment 2 with speeded item recognition, which was that facilitation for a target phrase appeared only with a prime from the same story and not a prime from the other story of the same MOP.

\section{General Discusson}

The main results from the experiments can be summarized as follows: For MOPrelated target phrases, responses can be facilitated by phrases from another story of the same MOP as well as by phrases of the target's own story. But for MOP-unrelated target phrases, responses are facilitated only by phrases of the same story as the target.

Secondary results ruled out possible alternative interpretations of the main results. Experiment 3 showed that the MOPrelated targets did not function as though they were synonymous and so eliminated synonymy as an explanation of the results of Experiment 1. Experiments 4 and 5 show that neither the results for MOP-related targets nor the results for MOP-unrelated targets depended on the target's story having a specific phrase parallel to the priming phrase in the other story. In Experiment 6, when subjects were asked to discriminate which phrases belonged to which stories, they did so (although not perfectly) for MOP-unrelated targets but not for MOPrelated targets.

Several models can be considered that could possibly account for these results. The "full copy model," one of the models suggested by Bower, Black, and Turner (1979), is based on the assumption that each episode or story for a MOP is encoded separately from any other story for that MOP. The representation for each story contains the information stated explicitly in the story plus default values for parts of the MOP that were not stated explicitly. Bower et al. pointed out that this model could not account for their data because it included no mechanism to account for confusions between two separate MOP stories. The model has the same problem in accounting for the data of the experiments presented here. There appears to be no way for information from one story to give facilitation to responses for test phrases from the other story of the same MOP.

A second model suggested by Bower et al. (1979) is the "partial-copy" model, mentioned in the introduction of this article. Recall that in this model, each story is encoded separately into memory, and that, in addition to the new structure for a story, both stated and unstated MOP actions are tagged in the generic representation of the MOP. This model can account for confusions about which action was stated in which story because of the tagging in the generic MOP representation. However, the model has difficulty with the results of Experiments 1 and 6. Both MOP-related target phrases and MOP-related priming phrases should be encoded into the new structure representing their stories, as well as being tagged in the generic MOP. When the prime and target presented for test are from the same story, the target should be facilitated both because prime and target are in the same new structure together and because they are tagged in the same generic MOP. When the prime and target share the same MOP but are from different stories, then the target should be facilitated only because it is tagged in the generic MOP. There should be facilitation in this condition, but it should be less than the facilitation observed when prime and target are from the same story. However, the data showed equal amounts of facilitation in the two conditions. The only way to make the partialcopy model fit the data is to assume that the equal amounts of facilitation are due to a floor effect on response times, but the times are slow enough (around $1280 \mathrm{~ms}$ ) that this seems unlikely. The partial-copy model would also suggest that subjects would be 
able to discriminate, for MOP-related targets, which target went with which story, but Experiment 6 failed to find such discrimination.

Another possible model would be a retrieval model, in which two stories of the same MOP were encoded completely separately, with no connections from the stories to a generic MOP. The generic MOP would only be used to add information to the separate encodings of the stories. If the MOPrelated information in the stories was encoded with an emphasis on its MOPrelatedness, then it might be the case that a MOP-related phrase from one of the stories would match information in both stories equally well. So there would be facilitation from MOP-related information in one of the stories to MOP-related information in the other story. Even though the stories were encoded completely separately, retrieval processes would produce matches that reflected the MOP relations. But this model can be ruled out because there would still be the problem that additional facilitation would be expected between phrases in the same story.

The partial copy model and the retrieval model exemplify the problems with most other models that might be considered: If explicitly stated story information is encoded in some way both in a new structure representing the story and in the generic MOP, then a MOP-related prime from the same story as a MOP-related target should give more facilitation than a prime from a different story of the same MOP, and subjects should be able to discriminate which MOP-related targets belong to which stories. On the other hand, if the information is encoded only in the new structure representing the story and not in the generic MOP, then there should not be facilitation from phrases in the other story of the same MOP. To accommodate all the results without these problems, we propose a model in which encoding is extremely limited.

According to the limited encoding model, no specific new structure is cncoded for a story. Instead, MOP-related events are simply tagged in the generic MOP representation. This representation is assumed to contain all the MOP-related events used in the stories. For example, in the Going to the beach MOP, after reading the two stories shown in Table 1 , the events in the generic MOP that represent spread towel in a dry place, found an empty space for blanket, dove into water, and strolled into the ocean would all be tagged, because they are all actions that are in the generic MOP because they frequently take place at the beach. Information in a story that was not related to the MOP would be encoded with pointers to the MOP-related information of the story. For example, watched the cliffs above for nesting swallows would be encoded with pointers to found an empty space for blanket, as well as to other MOPunrelated information.

The result of encoding is that the MOPrelated events are equally related to each other. While this would probably not be true for all sorts of MOP events (cf. Galambos \& Rips, 1982), it is plausible for the events used in the experiments in this article. Both the blanket and towel actions are tagged in the generic MOP, and we assume they are equally related to strolling into the ocean in the generic MOP. Thus they facilitate responses to strolling into the ocean equally well. MOP-unrelated targets are associated only with other MOP-unrelated information from the same story and with the generic MOP information that was stated in the same story, and so MOP-unrelated targets are facilitated only by other phrases from the same story.

The limited encoding model makes two strong assumptions. The first is that MOPrelated information is simply tagged in the generic MOP and no new copy of the information is encoded. This assumption is not unreasonable. Real world constraints may require minimizing processing time and effort. In addition, subjects in the experiments reported here soon realize that the storics are simple repetitions of sequences 
of events that contain no surprises. Of course, for stories in which the actions were not so similar, there might be different scenes, MOPs, or scripts involved in the two stories, and so there might be better discrimination.

The second strong assumption of the limited encoding model is that the range of priming effects is limited. While two MOPrelated phrases are closely associated enough to give facilitation to each other, one of them cannot give facilitation indirectly through the other to a MOPunrelated phrase. The only MOP-related phrases that can give facilitation to MOPunrelated phrases are those directly connected to the MOP-unrelated phrases by virtue of being in the same story. This assumption about the range of priming has empirical support from research with other kinds of associations. Ratcliff and McKoon (1988, Experiment 1) have shown that facilitation does not extend through the range of propositions of a story but instead is found only among propositions connected closely together in memory. de Groot (1983) and Balota and Lorch (1986) failed to find significant facilitation in lexical decision between pairs of words like lion and stripes which were thought to be mediated by $t i$ ger. McNamara and Altarriba (1988) did find a small amount of facilitation when highly associated pairs of words were excluded from the experiment, but this small effect can be attributed to a direct association (or feature overlap) between animals like lions and possible attributes of such animals' appearances (McKoon \& Ratcliff, $1989 \mathrm{e})$.

The limited range of priming effects is one of the empirical phenomena that supports a new view of priming proposed by Ratcliff and McKoon (1988; see also McKoon \& Ratcliff, 1988). According to this view, the facilitation given by a prime to a target is the result of the formation of a compound cue made up of the prime and target, and the joint strength of this compound in memory. In sharp contrast to spreading activation, this view does not assume that the prime activates some information in memory prior to the target. Instead, priming effects reflect the contents of the compound cue in short-term memory. Ratcliff and McKoon (1988) have shown that this compound cue theory is consistent with the empirical phenomena associated with priming effects, and also with several current general theories of memory (Anderson, 1983; Gillund \& Shiffrin, 1984; Hintzman, 1986; Murdock, 1982). The theory is especially consistent with the data from the experiments in this article. Intuitively, the compound cue notion captures the associative strength of prime-target compounds made up of two MOP-related phrases and the strength of prime-target compounds made up of two phrases from the same story. Because there is no activation to "spread" through links among nodes in memory, there is no natural expectation of priming spreading from a MOP-related phrase of one story to a MOPunrelated phrase of another story through generic MOP information.

The results of the experiments presented in this article, based on MOP knowledge structures, stand in opposition to the previous results obtained by Seifert et al. (1986; see also Seifert, Ableson \& McKoon, 1986), based on more general thematic structures. In the current experiments, a phrase from one story gave facilitation to a related phrase from another related story, but there was no such facilitation in the experiments in Seifert et al. The differences in results might be due to differences in the familiarity to the subjects of the generic structures (themes in Seifert et al. vs. MOPs in the current experiments). But it is more likely that the differences in results are due to the greater degree of content specificity in MOPs than in thematic structures. Thematic structures specify only a pattern of actions rather than what the particular actions might be; for example, the theme of revenge can be characterized by $\mathrm{X}$ doing something (unspecified) which is bad 
for $\mathrm{Y}$, and in response, $\mathrm{Y}$ does something (unspecified) which is bad for $\mathrm{X}$ (Lehnert, 1981). In contrast, the MOP structures specify much more of the action sequence: in going to the beach, one puts something on the sand to lie on and goes in the water. Because MOPs specify particular actions that occur in a sequence, they include much more content specific knowledge than thematic structures. It may be speculated that this specific concrete information is needed for two stories to be connected to the same generic structure in memory.

This experimental investigation began with the issue of reminding, and the retrieval of old, related episodes to help in the understanding and remembering of new episodes. For a story used in the experiments in this article, the most similar general structure in memory would be the story's MOP and the experimental results show that the story is encoded in terms of the MOP. However, the most similar specific structure in memory ought to have been the previously read story of that same structure, but the results do not support the encoding of story to story connections. It appears that events in one of the stories are not directly connected to events in the other story. Evidence for such connections has been obtained only when subjects are explicitly asked to rate the similarity of pairs of stories (Seifert et al., 1986).

The experiments reported here show that MOP episodes are encoded with respect to shared knowledge structures. Although previous research has demonstrated the role of such generic knowledge structures in retrieval (cf. Alba \& Hasher, 1983), the experiments in this article are the first to show the role of such structures in the encoding of new information. We view this research as one step in the examination of the complexities of the interactions of text processing and knowledge organization. In this way, the research has implications for the investigation of semantic memory, which despite extensive study a few years ago (cf. Collins \& Loftus, 1975; Smith,
Shoben, \& Rips, 1974; Ratcliff \& McKoon, 1982) has received little attention recently. We believe that investigating the characteristics of memory for general knowledge through interactions with text processing is a fruitful direction for research. Schank's (1982) theory of the use of larger, high level structures to encode and retrieve episodes is a potential route to progress, and the experiments reported use that theory to examine generic knowledge structures. Whether or not one subscribes to the theory, it provides a framework for formulating and addressing empirical questions about higher level knowledge structures.

\section{APPENDIX}

\section{MOP-related Primes, MOP-related} Targets, and MOP-unrelated Targets

\section{MOP 1 , Story 1}

spread her towel in a dry place.

dove into the refreshing water.

enjoyed the power of her executive secretary position.

\section{MOP 1, Story 2}

found an empty space for her blanket. slowly strolled out into the cool ocean. watched the cliffs above her for nesting swallows.

MOP 2, Story 1

were greeted at the door upon arriving. had chocolate mousse for dessert. pager indicated he was urgently needed.

\section{MOP 2, Story 2}

were shown to the cloakroom after entering. finished with creme caramel. wanted to make a good impression by chatting.

MOP 3, Story 1

let his co-workers know the details. sat back and listened for the doorbell. planned strategy for next week's business meeting.

MOP 3, Story 2

told his friends the date and time. paced around, anxious to greet his guests. favorite clothes were in the laundry.

\section{MOP 4, Story 1}

caught the bus to the shopping district. used a Mastercard to purchase shoes. saw a good friend across the street.

MOP 4, Story 2 got a ride from a classmate after school 
paid for the new sneakers by check.

was coming down with a cold.

MOP 5, Story 1

was told the plane would be leaving on schedule. sat down and buckled the safety strap. was scheduled to give a speech.

MOP 5, Story 2 saw the departure time on the flight listings. settled in and fastened the seat belt. spent the next hour anticipating the dinner menu.

MOP 6, Story 1

pulled himself out of bed.

bounded downstairs for a large breakfast. grabbed the flimsy wooden handrail, but it cracked.

MOP 6, Story 2

stretched and slowly got up.

jogged off into the kitchen.

had forgotten to park his convertible in the garage.

MOP 7, Story 1

finally found a spot to park.

carried his sleeping son out to the lot.

had caused quite a traffic jam in the parking lot.

MOP 7, Story 2

drove into the last empty space near the exit. headed for home, cheering wildly.

suggested to the group that they get some coffee.

\section{MOP 8, Story 1}

sat down because there were people ahead. examined the end product in the mirror. learned his trade in Germany many years ago.

MOP 8, Story 2

read the latest edition of "Harper's Bazaar." looked at the hairstyle from every angle. was extremely allergic to aerosols and anxious to get outside.

MOP 9, Story 1

walked up to the small counter.

checked that the transaction had been recorded. looked forward to having a high paying job.

MOP 9, Story 2

went over to the oak veneer desk.

examined the deposit receipt for errors.

tried to be pleasant while doing her work.

MOP 10, Story 1

wrote about being thrilled with the present. carefully placed the loving note in the mailbox. was recovering from a stroke at a convalescent home.

MOP 10, Story 2

detailed the new experiences at school.

dropped the letter at the post office.

had to hurry across campus to the lecture hall.
MOP 11, Story 1

sprayed the car all over with water.

put the car back into the garage.

would have preferred a long vacation.

MOP 11, Story 2

started hosing the car down.

parked the car along side of the house.

found a pair of socks that matched.

MOP 12, Story 1

finished making the deviled egg sandwiches.

folded up the old tablecloth.

rang the doorbell and found no one was at home.

MOP 12, Story 2

spent the morning preparing lunch.

picked up the blanket and food basket.

turned the radio up so everyone could hear.

MOP 13, Story 1

ran streamers across the ceiling.

passed cake to the hungry guests.

fell off and skinned his knees.

MOP 13, Story 2

confetti flew as the crowd began to show up.

everyone at the party ate happily.

couldn't get home for the party.

MOP 14, Story 1

the short ceremony ended with a kiss.

threw the bouquet in a friend's direction.

tripped while carrying a tray loaded with cham pagne.

MOP 14, Story 2

embraced the bride and proceeded out.

tossed the flowers to the girls.

had been working hard all day.

MOP 15, Story 1

loaded a huge tree into the pick-up.

strung the bulbs through the tree.

started a fight with his sister.

MOP 15, Story 2

tied a Norway Pine on the station wagon.

carefully draped some lights on each bough.

came to this country as a young girl.

MOP 16, Story 1

drove around the huge lot to find a spot.

trooped to the concession stand.

wanted milkshakes and bags of popcorn.

MOP 16, Story 2

had to search to get a good location to see.

walked to the refreshment building.

lots of teenagers were hanging around.

MOP 17, Story 1

answered some questions about travel plans.

carefully checked the ticket over.

rummaged through her purse for some kleenex. 
MOP 17, Story 2

discussed flexibility with schedules.

looked over the final itinerary.

looked at her watch, hoping it was time for lunch.

MOP 18, Story 1

remembered to floss carefully.

was snoring contentedly in less than five minutes. romped into the room, fighting and scratching.

\section{MOP 18, Story 2}

walked down the hall to brush teeth.

was soon fast asleep under the covers.

called from school to ask for an emergency loan.

MOP 19, Story 1

got Dad to drive to the movie house.

settled in for an enjoyable two hours.

paced angrily as he waited for help.

\section{MOP 19, Story 2}

was driven to the theater by an older brother. enthusiastically waited for the movie to begin. thought he smelled smoke out in the lobby.

\section{MOP 20, Story 1}

sat next to an old friend.

closed the notebook when the lecture ended.

slipped out quietly through the side entrance.

\section{MOP 20, Story 2}

took a seat that afforded a good view. packed up when the presentation was over. were working hard to fix the air conditioner.

\section{MOP 21, Story 1}

parked the car at MacDonald's and went inside. threw ont the garbage after finishing everything. got out to haul away a car.

\section{MOP 21, Story 2}

pulled up to a Burger King that was open.

bussed the tray after the food was gone.

could think of only one thing; driving the new car.

\section{REFERENCES}

alba, J. W., Alexander, S, Hasher, L., \& CanIGLIA, K. (1981). The role of context in the encoding of information. Journal of Experimental Psychology: Human Learning and Memory, 7, 283292.

ANDERSON, J. R. (1983). The architecture of cognition. Cambridge: Harvard University Press.

Balota, D. A., \& Lorch, R. F. (1986). Depth of automatic spreading activation: Mediated priming effects in pronunciation but not in lexical decision. Journal of Experimental Psychology: Learning, Memory, and Cognition, 12, 336-345.

Bower, G. H., Black, J. B., \& Turner, T. J. (1979). Scripts in memory for text. Cognitive Psychology, 11, 177-220.

Collins, A. M., \& Lofrus, E. F. (1975). A spread- ing-activation theory of semantic processing. Psychological Review, 82, 407-428.

DE Groot, A. M. B. (1983). The range of automatic spreading activation in word priming. Journal of Verbal Learning and Verbal Behavior, 22, 417436.

DYER, M. G. (1983). In-depth understanding: A computer model of integrated processing for narrative comprehension. Cambridge, MA: MIT Press.

Feldman, J. (1975). Bad-mouthing frames. In R. C. Schank \& B. Nash-Webber (Eds.), Theoretical issues in natural language processing. Cambridge, MA: Bolt, Beranek, \& Newman.

Galambos, J., \& Rips, L. (1982). Memory for routines. Journal of Verbal Learning and Verbal Behavior, 21, 260-281.

Gillund, G., \& Shiffrin, K. M. (1984). A retrieval model for both recognition and recall. Psychological Review, 19, 1-65.

Hintzman, D. (1986). "Schema abstraction" in a multiple-trace memory model. Psychological $R e$ view, 93, 411-428.

Lehnert, W. G. (1981). Plot units and narrative summarization. Cognitive Science, 5, 293-331.

McKoon, G., \& RatclifF, R. (1981). The comprehension processes and memory structures involved in instrumental inference. Journal of Verbal Learning and Verbal Behavior, 20, 671-682.

MCKoon, G., \& RATClifF, R. (1986). Inferences about predictable events. Journal of Experimental Psychology: Learning, Memory, and Cognition, 12, 82-91.

McKoon, G., \& RatclifF, R. (1988). Contextually relevant aspects of meaning. Journal of Experimental Psychology: Learning, Memory, and Cognition, 14, 331-343.

McKoon, G., \& Ratcliff, R. (1989a). Semantic association and elaborative inference. Journal of $E x$ perimental Psychology: Learning, Memory, and Cognition, 15, 326-338.

MCKoon, G., \& Ratcliff, R. (1989b). Dimensions of inference. The Psychology of Learning and Motivation, in press.

McKoon, G., \& Ratcliff, R. (1989c). Assessing the occurrence of elaborative inference with recognition: Compatibility checking vs. compound cue theory. Journal of Memory and Language, 28, 547-563.

McKoon, G., \& RAtcliff, R. (1989d). Textual inferences: Models and measures. In Rayner, Balota, \& D'Arcais (Eds.), in press.

McKoon, G., \& RAtcliff, R. (1989e). Spreading activation versus compound cue accounts of priming: Mediated priming revisited. In preparation.

McNamara, T. P., \& Altarriba, J. (1988). Depth of spreading activation revisited: Semantic mediated priming occurs in lexical decisions. Journal of Memory and Language, 27, 545-559. 
MiNSKY, M., (1975). A framework for representing knowledge. In P. Winston (Ed.), The psychology of computer vision. New York: McGraw-Hill.

MuRDock, B. B. (1982). A theory for the storage and retrieval of item and associative information. Psy. chological Review, 89, 609-626.

Ratcliff, R., \& McKoon, G. (1978). Priming in item recognition: Evidence for the propositional structure of sentences. Journal of Verbal Learning and Verbal Behavior, 17, 403-417.

RatclifF, R., \& McKoon, G. (1982). Speed and accuracy in the processing of false statements about semantic information. Journal of Experimental Psychology: Human Learning and Memory, 8, 16-36.

RATClifF, R., \& McKoon, G. (1981). Automatic and strategic priming in recognition. Journal of Verbal Learning and Verbal Behavior, 20, 204-215.

RatclifF, R., \& McKoon, G. (1988). A retrieval theory of priming in memory. Psychological Review, 95, 385-408.

RumelharT, D. E. (1980). Schemata: The building blocks of cognition. In R. J. Spiro, B. C. Bruce, \& W. F. Brewer (Eds.), Theoretical issues in reading comprehension. Hillsdale, NJ: Erlbaum.

Schank, R. C., \& Abelson, R. P. (1977). Scripts, plans, goals, and understanding. Hillsdale, NJ: Erlbaum.

Schank, R. C. (1982). Dynamic memory: A theory of reminding and learning in computers and people. New York: Cambridge University Press.

SEIFERT, C. M., \& BlaCK, J. B. (1983). Thematic connections between episodes. Proceedings of the Fifth Annual Conference of the Cognitive Science Society, Rochester, NY.

Seifert, C. M., Abelson, R. P., \& McKoon, G. (1986). The role of thematic knowledge structures in reminding. In J. A. Galambos \& R. P. Abelson (Eds.), Knowledge structures. Hillsdale, NJ: Earlbaum.

Seifert, C. M., McKoon, G., Abelson, R. P., \& RATClifF, R. (1986). Memory connections between thematically similar episodes. Journal of Experimental Psychology: Learning, Memory, and Cognition, 12, 220-231.

Smith, E. E., Shoben, E. J., \& Rips, L. J. (1974). Structure and process in semantic memory: A featural model for semantic decisions. Psychological Review, 81, 214-241.

(Received December 27, 1988)

(Revision received February 20, 1989) 